\title{
Helsesøstre har ikke rutinemessig spurt om foreldre utøver vold
}

Vold mot barn er et tema som har fått $\varnothing \mathrm{kt}$ oppmerksomhet, og mange barn utsettes for fysisk vold i oppveksten. Helsesøstre har plikt til å melde fra ved mistanke om fysisk vold mot barn. Flertallet av helseses $\varnothing$ strene mener fysisk vold mot barn kan avdekkes ved at de snakker med alle foreldre om temaet når de er på kontroller med barnet.

\section{Elisabeth Holm Hansen}

Førsteamanuensis

Fakultet for helse- og sosialvitenskap, Universitetet i Sørøst-Norge, Porsgrunn

Anne Ingebrigtsen

Helsesykepleier

Helsestasjon, Sandefjord kommune

Guri Odnakk

Helsesykepleier

Helsestasjon, Horten kommune

Marte Feiring Sollid

Helsesykepleier

Helsestasjon, Holmestrand kommune

Tonje Sundt-Schwebs

Helsesykepleier

Helsestasjon, Tønsberg kommune 


\section{Hovedbudskap}

En unders $\varnothing$ kelse blant 72 helses $\varnothing$ stre (nå helsesykepleiere) viser at det ikke spørres rutinemessig om foreldre ut øver vold mot barn. Derimot spørres det ofte ved mistanke, og da indirekte ved at helsesøstre forhører seg om grensesetting og sinnekontroll.

De aller fleste av helsesøstrene ønsker seg mer kunnskap og kompetanse om fysisk overgrep mot barn, symptomer og tegn på vold. Unders $\varnothing$ kelsen viser også at det er behov for å vite mer om hvordan det skal kommuniseres omkring temaet.

(NB: Undersøkelsen ble gjort før tittelen helsesykepleier ble innført. Vi har derfor valgt å benytte helsesøster konsekvent $i$ denne artikkelen.)

Tidligere helses $\varnothing$ sterstudenter ved Universitetet i S $\varnothing$ røstNorge gjennomf $\varnothing$ rte en unders $\varnothing$ kelse blant 72 helses $\varnothing$ stre om i hvilken grad de spør foreldre om de ut $\varnothing v e r$ fysisk vold mot barnet sitt, og hva som skal til for at helses $\varnothing$ stre kan avdekke slike forhold. Unders $\varnothing$ kelsen er foretatt $\mathrm{f} \varnothing \mathrm{r}$ «Vold, overgrep og omsorgssvikt» ble en del av helsestasjonsprogrammet.

\section{Mange barn utsettes for vold}

Vold mot barn er et tema som har fått økt oppmerksomhet, og mange barn utsettes for fysisk vold i oppveksten av foreldrene eller andre omsorgspersoner. Dette er et tabubelagt tema som preges av fortielse, skyld og skam for dem det gjelder, og følgene for barn som utsettes for fysisk vold er alvorlige $(1,2)$. Barnet befinner seg i en uholdbar omsorgssituasjon som kan føre til utrygghet og redusert helse og livskvalitet $(1,3,4)$.

\section{三 «Tall over hvor mange barn som utsettes for vold og overgrep i Norge, er vanskelig å finne.»}

Stortingsmelding nr. 15 definerer fysisk vold som enhver form for fysisk handling som skader eller kontrollerer barnet. «Fysisk vold inkluderer et vidt spekter av handlinger fra det å holde, dytte, riste eller klype, via bruk av slag, spark eller våpen til drap» (5).

Tall over hvor mange barn som utsettes for vold og overgrep i Norge er vanskelig å finne. Vold defineres ulikt, og gjør det vanskelig å sammenlikne forskningsstudier. Det er grunn til å tro at det finnes mørketall fordi mindre barn ikke inngår som primærkilde i eksisterende forskning (2). 


\section{Mer oppmerksomhet}

Det har de siste årene også vært økt oppmerksomhet om plikten ulike samfunnsakt $\varnothing$ rer, deriblant helses $\varnothing$ ster, har til å melde fra ved mistanke om fysisk vold mot barn. Forebyggede helsearbeid er en lovpålagt oppgave for kommunen (6) og formålet med helsestasjons- og skolehelsetjenesten er å fremme psykisk og fysisk helse, fremme gode og sosiale miljømessige forhold og forebygge sykdom og skade (7). Helsestasjon jobber mot barn fra 0-5 år og deres foreldre, og helsesøster er en av instansene som skal sørge for at barn mottar den hjelpen de har behov for.

Til tross for meldeplikten, er det likevel ikke helsestasjonen som har den st $\varnothing$ rste meldingsandelen til barnevernet (8). Etter at denne unders $\varnothing$ kelsen ble gjennomført har vold mot barn blitt et eget tema i Nasjonal faglig retningslinje for det helsefremmende og forebyggende arbeidet i helsestasjon, skolehelsetjeneste og helsestasjon for ungdom (7). Helses $\varnothing$ stre har derimot vært omfattet av helsepersonelloven som sier at helsepersonell uten hinder av taushetsplikten, har opplysningsplikt til barnevernet i saker der det er mistanke om vold eller overgrep mot barn (9).

\section{Resultat}

I alt 98 spørreskjemaer ble sendt ut til 12 helsestasjoner, og totalt 72 helses $\varnothing$ stre besvarte skjemaene, noe som ga en svarprosent på 73 prosent. Over halvparten hadde arbeidserfaring som helsesøster i mer enn 10 år, mens de resterende fordelte seg ganske likt på o-5 år og 5-10 år.

Unders $\varnothing$ kelsen viste at helses $\varnothing$ strene hadde gode rutiner for å spørre foreldrene om fysisk vold ved mistanke (75 prosent), mens 8 prosent av helses $\varnothing$ strene oppga at de aldri spurte. Av dem som svarte at de alltid spurte, var det flest helses $\varnothing$ stre med mer enn 10 års erfaring, men det var ingen signifikant forskjell i hvilken grad helsesøstrene spurte om fysisk vold og hvor lang helsesøstererfaring de hadde.

Tabell 1. Andel helses $\varnothing$ stre i de ulike erfaringskategoriene og om de spør foreldre om fysisk vold. $(\mathrm{N}=72)$

\begin{tabular}{lllll}
\hline Spør du foreldrene: & Erfaring $<\mathbf{5}$ år & Erfaring 5-10 år & Erfaring $>\mathbf{1 0}$ år & Totalt $\mathbf{n}(\%)$ \\
Aldri & $1(6)$ & $1(6)$ & $4(11)$ & $6(8)$ \\
Bare ved mistanke & $15(88)$ & $16(89)$ & $23(62)$ & $54(75)$ \\
Annet & $1(6)$ & $1(5)$ & $10(27)$ & $12(17)$ \\
Totalt & $17(100)$ & $18(100)$ & $37(100)$ & $72(100)$ \\
\hline
\end{tabular}


Helsesøstrene som svarte at de «aldri» spurte foreldre om fysisk vold mot barna, ble bedt om å begrunne svaret i form av gitte svaralternativer. Helsesøstrene svarte at vold mot barn var et vanskelig tema å ta opp, at det å spørre ikke inngikk i det anbefalte helsestasjonsprogrammet, og at de var usikre på hvordan de skulle håndtere forhold som eventuelt ble avdekket.

Av dem som svarte «annet», fant vi noen gjennomgående temaer. Helses $\varnothing$ strene tok opp temaet fysisk vold indirekte i forbindelse med «grensesetting», «sinnekontroll» og «ved mistanke om rus og psykiske lidelser». Det kom ikke frem av svarene om helsesøster spurte direkte om vold. En større andel av helses $\varnothing$ stre med mer enn ti års erfaring var usikre på om vold mot barn kan avdekkes ved å spørre alle foreldre enn de med mindre erfaring. Det var derimot ikke signifikante forskjeller mellom gruppene med ulik helsesøstererfaring.

28 prosent av helses $\varnothing$ strene svarte at det var viktig å spørre om fysisk vold ved første møte med foreldrene, altså ved hjemmebes $\varnothing \mathrm{k} .15$ prosent mente helses $\varnothing$ ster bør spørre ved alle konsultasjoner, og svært få mente at det ikke var nødvendig å spørre i det hele tatt. 56 prosent krysset av på «annet». Svarene fra helsesøstrene under «annet» var konkrete forslag, og alle ble samlet i kategorier som vist i tabell 2.

Tabell 2. Forslag fra helsesøstre som svarte «annet» under hvilken konsultasjon det var viktig å spørre om fysisk vold. $(n=40)$.

\begin{tabular}{ll} 
Forslag til når helses $\varnothing$ stre bør spørre & Antall \\
Regelmessig & 12 \\
$2-4$ års konsultasjon & 11 \\
Ved mistanke & 8 \\
1 års konsultasjon & 8 \\
Hjemmebes $\varnothing$ k & 7 \\
18 mnd. konsultasjon & 5 \\
6 ukers konsultasjon & 3 \\
$6-9$ mnd. konsultasjon & 3 \\
\hline Noen av informantene krysset av for mer enn ett forslag til når helses $\varnothing$ ster bør spørre om fysisk vold. &
\end{tabular}

Hva helses $\varnothing$ strene vektla som viktige faktorer for å avdekke fysisk vold, fordelte seg jevnt som vist i tabell 3 . 
Tabell 3. Faktorer som må være tilstede for å avdekke fysisk vold. (N=72)

At helsesøster har tilstrekkelig kunnskap om tegn på at barnet utsettes for fysisk vold

De som krysset av for «annet», etterlyste tiltaksplan og retningslinjer for å følge opp det som ble avdekket.

Om variabelen «opparbeidet tillit hos foreldrene» var en viktig faktor for å avdekke fysisk vold hos barn, var det signifikante forskjeller mellom helsesøstre og ulik arbeidserfaring. For dem med minst og lengst helses $\varnothing$ stererfaring var dette ansett som viktig (71 prosent og 65 prosent), mens i gruppen 5-10 år var det en tredel som anså opparbeidet tillit hos foreldre som viktig for å avdekke vold hos barn.

Unders $\varnothing$ kelsen viste at 82 prosent av helses $\varnothing$ strene mente de hadde behov for mer kunnskap. 13 prosent svarte «nei», og 5 prosent var usikre. Det var ingen signifikante forskjeller mellom erfaring som helses $\varnothing$ ster og oppgitt behov for kunnskap. Av dem som mente de hadde behov for mer kunnskap, var det 11 helsesøstre som ikke utdypet dette nærmere. Tabell 4 viser hva de $\varnothing$ vrige helses $\varnothing$ strene $\varnothing$ nsket mer kunnskap om. I kategorien «generell kunnskap», kom det frem kommentarer om at det alltid er behov for mer kunnskap, og at det er viktig å holde seg oppdatert.

Tabell 4. Hva helses $\varnothing$ strene $\varnothing$ nsket mer kunnskap om $(n=48)$

$\begin{array}{ll}\text { Kunnskapsbehov } & \text { Antall } \\ \text { Kommunikasjonsferdigheter } & 25 \\ \text { Generell kunnskap } & 16 \\ \text { Kunnskap om tegn på fysisk vold } & 10 \\ \text { Kunnskap om oppdragervold } & 2 \\ \text { Kunnskap om loven og melderutiner } & 1\end{array}$


Flertallet av helseses $\varnothing$ strene mente fysisk vold mot barn kan avdekkes ved at de spør alle foreldre (65 prosent), mens 8 prosent svarte «nei» og 27 prosent svarte «vet ikke». Videre mente 82 prosent av alle helsesøstrene at spørsmål om vold mot barn bør inngå i det anbefalte helsestasjonsprogrammet. Det var ikke signifikante forskjeller mellom erfaring som helsesøster og om det å spørre om vold hos barn bør inngå i helsestasjonsprogrammet.

\section{Metode}

Data ble innhentet gjennom en kvantitativ spørreunders $\varnothing$ kelse. Dette ble samlet inn av helses $\varnothing$ sterstudenter ved videreutdanningen ved Universitetet i Sørøst-Norge i forbindelse med avsluttende fordypningsoppgave (i 2015). Et spørreskjema med faste svaralternativer ble utarbeidet på bakgrunn av hva vi ønsket svar på. Det ble lagt inn mulighet for å komme med konkrete forslag ved enkelte spørsmål slik at eventuelle manglende svaralternativer kunne spesifiseres.

14 helsestasjoner fra Østlandet ble invitert til å delta i spørreundersøkelsen, og det ble tatt kontakt med ledende helses $\varnothing$ ster ved de respektive helsestasjonene som fikk muntlig og skriftlig informasjon. Utvalget besto av helsesøstre som var ansatt på helsestasjon, og totalt 98 spørreskjemaer ble sendt ut i februar 2015. Det ble purret på spørreskjemaene én gang ved alle helsestasjonene.

\section{Analyse}

Kategorien «annet» var en åpen kategori i fire av spørsmålene. Svarene under «annet» ble skrevet i fritekst med konkrete forslag. Forslagene ble systematisert i nye kategorier som igjen ble kodet for analyse. Svarene fra «annet» er presentert i tabell 2 og 4 . Helsesøsters arbeidserfaring var en variabel som ble fordelt til tre kategorier < 5 år, 5-10år og >10år. Datamaterialet ble kodet og analysert i SPSS (versjon 22, 2013) og vi ønsket å se om det var signifikante forskjeller mellom helsesøsters erfaring og følgende variabler:

1. Om helses $\varnothing$ ster spør foreldrene om fysisk vold.

2. Om fysisk vold kan avdekkes ved at helsesøster spør.

3. Ved hvilken konsultasjon helsesøster bør spørre.

4. Hvilken kompetanse som er viktig for å avdekke fysisk vold hos barn. 
5. Om helses $\emptyset$ ster har behov for mer kunnskap om fysisk vold.

6. Om det å spørre om fysisk vold bør inngå i det anbefalte helsestasjonsprogrammet.

\section{Diskusjon}

Funnene i denne unders $\varnothing$ kelsen viste at det ikke var vanlig å stille rutinemessige spørsmål for å avdekke fysisk vold hos barn. Det var heller ingen forskjell mellom helsesøsters arbeidserfaring og i hvilken grad hun/han spurte. Flertallet svarte at årsaken til at det ikke spørres, var at det den gang ikke inngikk i det anbefalte helsestasjonsprogrammet. Disse funnene var i tråd med studentenes observasjoner fra praksis ved ulike helsestasjoner der erfaringen var at foreldre aldri ble spurt direkte om de utøver fysisk vold mot barnet sitt.

Det var heller ingen rutine for å ta opp temaet med foreldrene. Derimot spurte en stor andel av helses $\varnothing$ strene i denne unders $\varnothing$ kelsen ved mistanke. Det kom ikke frem hva helses $\varnothing$ strene la i begrepet mistanke og hva som eventuelt ga dem en mistanke. Fordi mistanke er et lite nøyaktig begrep er regelmessige spørsmål til foreldre desto viktigere.

\section{$\equiv$ «Foreldre som utøver mild fysisk vold mot barna sine, innrømmer det når det spørres om foreldrene klasker eller klyper barna.»}

I en Canadisk studie kom det frem at flere av sykepleierne opplevde loven tvetydig når de skulle tolke begrepet «mistanke», og hva som ligger i «rimelig grad av mistanke» (10). En annen studie viste også at begrepet rimelig grad av mistanke ble oppfattet svært ulikt blant sykepleiere og andre helsearbeidere (11). Barneloven i Norge ble endret i 2010, og mange foreldre vet kanskje ikke at å klaske og klype barn ikke er lov, selv om det benyttes som et ledd i oppdragelsen (12).

Flere av helses $\varnothing$ strene i sp $\varnothing$ rreunders $\varnothing$ kelsen mente at det var viktig at helses $\varnothing$ ster spør om foreldrene utøver fysisk vold mot barna, men at ordet «vold» ikke burde brukes. Når temaet ble tatt opp, ble det gjort ved å spørre indirekte for å danne seg et bilde av hvordan foreldrene håndterte grensesetting og hvordan de kontrollerte sitt eget sinne. Solveig Ude, som har lang erfaring som helsesøster, viser til at foreldre som ut $\varnothing$ ver mild fysisk vold mot barna sine innrømmer det når det spørres om foreldrene klasker eller klyper barna (13). 


\section{Tid er en viktig faktor}

Flere av helsesøstrene i denne studien svarte at tid er en viktig faktor for å kunne avdekke fysisk vold mot barn. Dette samstemte med observasjoner gjort under praksisoppholdet på helsestasjon, hvor konsultasjonene ofte var korte og arbeidsoppgavene mange. Helses $\emptyset$ sterstudentene opplevde at det var liten tid til å snakke om og følge opp vanskelige temaer.

Helses $\varnothing$ strene syntes det var vanskelig å stille spørsmål om fysisk vold, og at de opplevde at de «tradisjonelle» helsestasjonsrutinene tok det meste av tiden. Til tross for dette var ikke «tid» den hyppigste oppgitte årsaken $\mathrm{i}$ unders $\varnothing$ kelsen til at tema vold ikke ble tatt opp ved helsestasjonene.

\section{Mangler kunnskap}

I lov om kommunale helse- og omsorgstjenester (7) vises det til at kommunen har et ansvar for at helsesøster har nødvendig kompetanse og ressurser, og at helsesøster selv er pliktig til å holde seg faglig oppdatert (6). Informantene oppga at de hadde behov for mer kunnskap (82 prosent). Det kom frem at helsesøstrene var usikre på hvilken atferd hos barnet som kan gi dem mistanke om vold, og hva de skal se etter i samspillet mellom foreldrene og barnet. Utfordringen var å definere hva som er normal barneatferd, og hva som bør gi bekymring.

Studier fra USA har vist at mangel på kunnskap som symptomer og tegn på vold, etiske vurderinger og hvordan saker skal rapporteres er mangelfulle hos helsepersonell generelt (14-17).

\section{三 «Helsesøstrene svarte at det er viktig med gode kommunikasjonsferdigheter og erfaring med å stille spørsmål om fysisk vold.»}

Det var små forskjeller i hva helses $\varnothing$ strene vektla som viktige

faktorer for å avdekke fysisk vold, men flesteparten av

helses $\varnothing$ strene etterlyste mer kunnskap om tidlige tegn på at barn utsettes for fysisk vold og hvordan de kan snakke med foreldrene om temaet. 
Over halvparten av informantene i vår unders $\varnothing$ kelse svarte at det er viktig med gode kommunikasjonsferdigheter og erfaring med å stille spørsmål om fysisk vold. Det vil være naturlig å tenke at ved å øke denne kompetansen ville det bli lettere å ta opp temaet fysisk vold uten at tilliten brytes.

Flere utenlandske studier har vist at helsepersonell følte seg tryggere på å melde fra om vold når de hadde fått opplæring og hadde erfaring. Relevant kunnskap økte sannsynligheten for at de meldte fra ved mistanke om vold mot barn og at de meldte korrekt (18-20). Helses $\varnothing$ strene i vår spørreunders $\varnothing$ kelsen understreket betydningen av mer undervisning om temaet i helses $\varnothing$ sterutdanningene.

\section{Tillit kan svekkes}

Mange helses $\varnothing$ stre svarte at det er viktig å ha et godt forhold til familien basert på samarbeid og tillit og syntes det var vanskelig å ta opp temaet vold uten at denne tilliten ble svekket. Det kan se ut som om helsesøster opplever det som et dilemma, og at de ikke ønsker at helsestasjonen skal bli et «kontrollstasjon». Sykepleierne ønsker ikke å ødelegge relasjonen til familien og usikkerhet omkring situasjoner gjorde at de lot vær å kartlegge nærmere. Studier har vist at helsepersonell er redd for konsekvensene av avdekking og melding av barnevernssaker (16).

Flere enn halvparten av helses $\varnothing$ strene i unders $\varnothing$ kelsen mente at fysisk vold mot barn kan avdekkes gjennom systematisk kartlegging, og flere enn tre firedeler mente det burde inngå i det anbefalte helsestasjonsprogrammet. Slik kan det virke som at helsesøstrene er positive til at det implementeres. Om ikke annet blir de «tvunget» til å spørre.

«Veileder til forskrift om kommunens helsefremmende og forebyggende arbeid i helsestasjons- og skolehelsetjenesten» ble erstattet av «Nasjonal faglig retningslinje for det helsefremmende og forebyggende arbeidet i helsestasjon, skolehelsetjeneste og helsestasjon for ungdom» (7). Kapittel om Helsestasjon 0-5 år ble publisert 9. februar 2017, og retningslinjen ble oppdatert i august 2018.

\section{«At vold og overgrep har blitt et tema i ny faglig retningslinje, har forsterket plikten helsesøstrene har til å melde ifra til Barnevernet.»}


Selv om denne studien ble foretatt før den faglige retningslinjen kom, der vold og overgrep ble et tema i ny retningslinje, har helsepersonell alltid vært omfattet av lov om helsepersonell (9). Der står det at helsepersonell uten hinder av taushetsplikt, og på eget initiativ umiddelbart, skal melde fra til barnevernstjenesten når det er grunn til å tro at et barn blir mishandlet i hjemmet eller det foreligger andre former for alvorlig omsorgssvikt. At vold og overgrep har blitt et tema i ny faglig retningslinje, har forsterket plikten helsesøstre har til å melde ifra til Barnevernet, og man kan anta at en tydeliggjøring i retningslinjene kan ha påvirket helsesøsters praksis.

I unders $\varnothing$ kelsen kom det frem behov for kunnskap om tidlig symptomer og tegn og kunnskap om hvordan de skal kommunisere om temaet. I tillegg har landsgruppen av helses $\emptyset$ stres utarbeidet eget materiell som skal benyttes for å forebygge, avdekke og avverge vold på helsestasjonen.

Materiellet kan brukes i samtale med foreldre og består av en animasjonsfilm og et veiledningshefte for helses $\emptyset$ stre. Det er anbefalt at materiellet benyttes på hjemmebes $\varnothing \mathrm{k}, \mathrm{i}$ barselgruppe og/eller seksukerskontrollen. Helsedirektoratet støtter filmen, og materiellet er utarbeidet slik at helses $\varnothing$ stre med sin kompetanse kan ta det i bruk uten opplæring.

\section{Konklusjon}

Det kom frem i denne unders $\varnothing$ kelsen at helsesøstre på helsestasjon ikke spør rutinemessig om foreldre utøver vold mot barn. Derimot spørres det ofte ved mistanke og da indirekte ved at helsesøster spør om grensesetting og sinnekontroll. Mer kunnskap og kompetanse om fysisk overgrep mot barn, symptomer og tegn var et ønske fra de aller fleste helses $\varnothing$ strene.

En stor andel mente også at det burde inngå i helsestasjonsprogrammet slik at man måtte spørre. Behov for kunnskap om hvordan det skal kommuniseres omkring temaet, var også en viktig tilbakemelding fra helses $\varnothing$ strene i studien. Opparbeidet tillit til familier ble nevnt som en viktig barriere for å avdekke vold, mens nok tid ikke var den avgjørende grunnen til at helses $\varnothing$ stre ikke spurte. I dag er temaet vold og overgrep inkludert i helsestasjonsprogrammet, og det er utarbeidet materiell som helses $\emptyset$ ster kan benytte i møte med familier. Dette kan både ha forsterket og hjulpet helses $\varnothing$ stre til å identifisere utsatte barn. 


\section{Referanser}

1. Dorahy MJ, Middleton W, Seager L, Williams M, Chambers

R. Child abuse and neglect in complex dissociative disorder, abuse-related chronic PTSD, and mixed psychiatric samples. J Trauma Dissociation. 2016;17(2):223-36.

2. Kruse AE, Bergmann S. «Jeg kan jo ikke kalle det noe annet enn vold ...» En forskningsoversikt og en intervjustudie om mødres vold mot barn. Oslo: Nasjonalt kunnskapssenter om vold og traumatisk stress; 2014. Rapport 4/2014. Tilgjengelig fra: https://www.nkvts.no/rapport/jeg-kan-jo-ikke-kalle-detnoe-annet-enn-vold-en-forskningsoversikt-og-enintervjustudie-om-modres-vold-mot-barn/ (nedlastet 16.10.18).

3. Thoresen S, Myhre M, Wentzel-Larsen T, Aakvaag HF, Hjemdal OK. Violence against children, later victimisation, and mental health: a cross-sectional study of the general Norwegian population. Eur J Psychotraumatol. 2015 januar; $13(6): 26259$.

4. Halvorsen S, Killén K, Grøgaard J. Why do we overlook child abuse? Tidsskr Nor Legeforen. 2013;133:16-7.

5. Meld. St. 15 (2012-2013). Forebygging og bekjempelse av vold i nære relasjoner. Det handler om å leve. Oslo: Justis- og beredskapsdepartement; 2013. Tilgjengelig fra:

https://www.regjeringen.no/no/dokumenter/meld-st-1520122013/id716442/ (nedlastet 16.10.2018).

6. Lov 1. januar 2012 om kommunale helse- og omsorgstjenester (helse- og omsorgstjenesteloven). Oslo; Helse- og omsorgsdepartementet; 2012.

7. Helsedirektoratet. Nasjonal faglig retningslinje for det helsefremmende og forebyggende arbeidet i helsestasjon, skolehelsetjeneste og helsestasjon for ungdom. Oslo:

Helsedirektoratet; 2017. Tilgjengelig fra:

https://helsedirektoratet.no/retningslinjer/helsestasjons-ogskolehelsetjenesten (nedlastet 27.11.18).

8. Barne-, ungdoms- og familiedirektoratet. Meldinger til barnevernet. Oslo: Barne,- ungdoms- og familiedirektoratet; 2017. Tilgjengelig fra:

https://www.bufdir.no/Statistikk_og_analyse/Barnevern/Beky mringsmeldinger (nedlastet 27.11.18). 
9. Lov 2. juni $1999 \mathrm{nr} .64$ lov om helsepersonell m.v. (helsepersonelloven). Oslo: Helse- og omsorgsdepartementet; 1999.

10. Tiyyagura G, Gawel M, Koziel JR, Asnes A, Bechtel K. Barriers and facilitators to detecting child abuse and neglect in general emergency departements. Ann Emerg Med. 2015 november; 66(5):447-54.

11. Pietrantonio AM, Wright E, Gibson KN, Alldred T, Jacobson D, Niec A. Mandatory reporting of child abuse and neglect: crafting a positive process for health professionals and caregivers. Child Abuse Negl. 2013; 37(2-3):102-9.

12. Lov 1. januar $1982 \mathrm{nr} .7$ om barn og foreldre (barnelova). Oslo: Barne- og likestillingsdepartementet; 1982.

13. Ude S. Derfor spør jeg foreldrene. Aftenposten 3. september 2014 .

14. Laherty EG, Sege R. Barriers to physician identification and reporting of child abuse. Pediatr Ann. 2005 mai;34(5):349-56.

15. Alvarez KM, Kenny BD, Carpin KM. Why are professionals failing to report mandated reports of child maltreatment, and are there any empirically based training programs to assist professionals in the reporting process? Agression and Violent behavior. 2004;9:653-578.

16. Schols MW, de Ruiter C, Öry FG. How do public child healthcare professionals and primary school teachers identify and handle child abuse cases? A qualitative study. BMC Public Health. 2013 september;13:807.

17. Fraser JA, Mathews B, Walsh K, Chen L, Dunne M. Factors influencing child abuse and neglect recognition and reporting by nurses: a multivariate analysis. Int J Nurs Stud. 2010 februar; $47(2): 146-53$.

18. Flaherty EG, Sege R, Binns HJ, Mattson CL, Christoffel KK. Health care providers' experience reporting child abuse in the primary care setting. Pediatric Practice Research Group. Arch Pediatr Adolesc Med. 2000 mai;154(5):489-93. 
19. Lagerberg D. A descriptive survey of Swedish child health nurses' awareness of abuse and neglect. I. Characteristics of the nurses. Child Abuse Negl. 2001 desember;25 (12):1583601.

20. MacMillan HL, Thomas BH, Jamieson E, Walsh CA, Boyle MH, Shannon HS, et al. Effectiveness of home visitation by public-health nurses in prevention of the recurrence of child physical abuse and neglect: A randomised controlled trial. Lancet. 2005 mai;365(9473):1786-93. 